\title{
The materiality of performance in Mycenaean funerary practices
}

\author{
Michael J. Boyd
}

\section{Introduction}

Tombs are a common, if unevenly distributed, aspect of the archaeology of late Bronze Age Greece (Cavanagh and Mee 1998), and they have played a significant role in the interpretation of the nature of prehistoric communities since the days of Schliemann's excavations at Mycenae in 1876 (Schliemann 1878). Two aspects have received much scholarly attention: architectural elaboration and their material contents, of which the most spectacular examples are the shaft graves excavated by Schliemann. In this article, by refocusing attention on funerals as spectacles, I reconsider the second of these aspects, using the well-known example of Routsi tholos 2 in the south-western Peloponnese.

The deposition of material in the grave is not a necessary act in the disposal of a corpse, even where other aspects of ritual or performance may be developed. In some prehistoric societies mortuary activities do not usually involve placing material in the grave. This is true of some earlier middle Bronze Age communities of mainland Greece (Cavanagh and Mee 1998, 31; Dickinson 1977, 33-4). The development and employment of visible and public funerary practices involving deposition are therefore of great interest: in what contexts did such practices develop, how were they motivated and what can we glean about the nature, intentions and significance of the material performances of which they formed a part?

When confronted with an assemblage we face the task of understanding alien objects now remote from their contexts of production and use. Some approaches to the material culture of Mycenaean tombs in scholarly literature involve objects reflecting material requirements (and perhaps a few luxuries) for the dead on entering the afterlife. For other researchers, grave goods reflect the wealth or status the dead attained in life. In both approaches, meaning is ascribed to grave assemblages as a whole and in a normative fashion. Each individual object contributes to an overall picture which is predictable and comparable from site to site (Barrett 2001, 143). The broad applicability of the interpretation - any item can be explained as having belonged to the dead and any item can be said to reflect status, whether elevated or humble - precludes the possibility that any new find could alter or refine our understanding of how material culture was used in Mycenaean mortuary practices. Instead, additional excavations simply reconfirm what we already know - which, predictability, militates against improved recovery strategies or further study.

Typologies are similarly used to bring order to a disparate group of materials. In the material rich prehistoric Aegean, typologies have been highly refined: by grouping and bounding, by judging likeness and relation through physical characteristics such as form, decoration and technological process (Harrell forthcoming; Morris 1994), a meaning for a particular item can then be derived by identification, rather than from interpreting its role in the burial context. One assemblage as a whole can be judged in comparison to assemblages from other tomb groups.

Alternative approaches to material culture have highlighted its active and meaningful constitution (Hodder 1982; Shanks and Tilley 1987, 107, 114; Shanks and Tilley 1992, 121-33). More recent approaches emphasize human agency and its complex relationships with artefacts and the material world (Robb 2004, 2010), as well as the material structural conditions within which agency is necessarily situated (Barrett 2000, 2001). These approaches require a more sensitive approach to both action and context: typological approaches de-emphasize context and mask the results of individual action. A detailed consideration of context (an archaeology of inhabitation: Barrett 2000, 67) is essential to a reconstruction of the human actions involved in its reproduction. To understand material culture and its role in the funerary process, therefore, we need to develop a contextualized understanding of its use in past action as well as a self-critical analysis of contemporary knowledge claims. In this paper, through a re-focusing of attention on performance, the significance of agency (and its materiality) in the creation of tomb deposits becomes clear. 


\section{Contextualizing material performances}

Past contexts of action are the locales for action as apprehended by agents. They incorporate, with fluctuating degrees of importance and immediacy, the actor's perceptions and memory mediated understandings of environment, surroundings, architecture, material culture and the presence and intentions of others. This understanding of locale is profoundly relational (Robb 2010, 494) and in constant flux as the agent monitors the results of her or others' actions or interactions with elements of the locale including those others with her, and as these observations are processed into memory. Understandings of locale were also scalar and hierarchical, incorporating elements of habitus and fields of action, as well as specific and instantiated conditions of action (Robb 2010, 506).

Because these past contexts of action existed only fleetingly - as an understanding of conditions in the moment of action - they were never fixed and cannot therefore be equated with particular durable physical characteristics. Nonetheless, physical characteristics - topographical, architectural and material - played important roles in structuring the conditions of action, and their residues remain for us to study. Unlike architecture and physical settings, material culture has the distinction of portability, and hence it can be deployed strategically to introduce nuances to each actor's understanding of locale. This manipulation of material culture - and, in tomb contexts, manipulation of architecture through the digging or filling of graves, opening or closing of tombs - is part of what Thomas calls 'the production of context' $(1996,171)$ - the reordering of things, people and places as part of the continuous re-structuring of locale to present certain practices as meaningful in particular ways.

In funerary archaeology the action is likely to be exceptional rather than routine, as well as occasional rather than everyday. These characteristics are reminiscent of Schechner's definition of performance: 'Behavior heightened, if ever so slightly, and publicly displayed; twice-behaved behavior' (1993, 1). Performance is produced in discursive consciousness (Giddens 1984) aimed at achieving certain goals while cognizant of the scrutiny of those co-present, the affordances of place (Dakouri-Hild and Boyd forthcoming) and 'tradition' as shared, negotiable memory of past performances. Contextualized, or 'site-specific', performance 'is the latest occupation of a location at which other occupations - their material traces and histories - are still apparent...interpenetrating narratives jostle to create meanings' (Pearson and Shanks 2001, 23). In funerary performances participants are drawn to the grave to locate the dead amid these interpenetrating narratives whose physical manifestation is the tomb and its material contents.

Some recent writing on performance in prehistory emphasizes large-scale public spectacles and the performance of elite power (Inomata and Coben 2006, though see Hodder 2006). Monumental architecture and large audiences have been taken as key aspects of spectacle by some researchers, while for others the role of material culture (in the form of costumes or objects for display) is also prominent (DeMarrais, Castillo and Earle 1996). Performance in the enclosed space of the tomb or performances encompassing modest groups of the scale of smaller communities or specific corporate groups may be more relevant for understanding most Mycenaean funerals. At this smaller scale, the notion of a public spectacle is still appropriate, as the event is staged in relation to the numbers involved and overall community size. In particular, it may be argued that material culture plays a particularly crucial role in creating spectacle in these funerary events.

While much archaeological deposition is an unintended consequence of routine practice, tombs and graves are unusual in that deposition is often the intended outcome of action. The close observation of archaeological and stratigraphic context allows us a partial reconstruction both of the past conditions of action and of the action itself. The presence of an object in a tomb therefore suggests both the act of depositing of the object and that cognizance of its presence and meaning then formed part of the further context of action in the tomb. These form unusually advantageous conditions in which to understand the funerary performance through such concepts as relational and material agency (Robb 2004, 2010), material engagement processes (Renfrew 2004, 29) or the materialization of culture (DeMarrais 2004).

Mycenaean tombs are nevertheless challenging case studies for this interpretative approach. Most conform to a tripartite plan of entrance passage ('dromos'), entrance ('stomion') and chamber. The majority are rock-cut and underground ('chamber tombs'), while a minority consists of stone-built structures, often covered by a mound ('tholos tombs'). Others, such as the shaft graves of Mycenae itself, are rare. The tholos and chamber tombs are multiple-use tombs, as were the shaft graves (though in a different way: Boyd in press). Multiple-use tombs present specific challenges for understanding depositional contexts, since each new action in the tomb leads to dispositional rearrangement, compromising the integrity of prior contexts. Moreover we have to be alert as to whether the disturbance of material is (as is often assumed) a kind of accidental by-product of the latest 
interment process or a consequence of a more complex series of meaningful actions that might be reconstructed. It is unfortunately the case that the disposition of material in tombs is often taken as self-evidently selfexplanatory, leading to a lack of detail in excavation reports, and often in excavation recording.

\section{Material performance and the tempo of the funeral}

The evidence available to us for interpreting Mycenaean funerary rites is that deposited in the grave at the end of the funeral. This assemblage represents a late moment in the funerary performance: activities at other places will already have taken place. We can reconstruct a partial framework for these events by interpreting the materials found in the tomb, dividing them into three basic groups according to their mode of use in the funeral. For example, the final burial at Routsi tholos 2 in the south-western Peloponnese (Boyd 2002, 153-9; Korrés 1982; Marinatos 1957a, 1957b; Figs 1 and 2) was an extended adult burial which, unusually, had not been subsequently disturbed. It therefore probably represents the funerary context as created at the time of the funeral (though see Korres 1982 for an alternative hypothesis). The skeleton lay on its back on the floor of the chamber, feet towards the entrance. The majority of items associated with it were set on its right side: ten pots at the feet and head, and metal items - ten (or eleven) swords and knives, a spearhead and a mirror - in between. Other items were found among the bones: elements of an amber necklace around the neck and fifteen sealstones in the area of the hands; a lone metal object had been placed on the left side.

Each of these objects was employed in the performance of the funeral, and only its final role - being placed carefully in relation to the corpse - is directly evident. However, the modes of use of the objects are clear. Some items - the necklace and perhaps the sealstones, threaded as a bracelet - were used as adornments for the body of the deceased. Although it is possible that these were placed on the corpse after deposition, they more likely played a role in an early stage of the funeral as part of the preparation of the corpse for burial (Boyd forthcoming a). The swords, knives, mirror and spearhead were placed beside the dead, creating its immediate material context. In some ways, these objects create an extra-somatic extension to the adornments on the body, but the pathway of their manipulation throughout the funerary process would have differed. These objects must either have been carried separately, by different participants, or have been arrayed with the corpse on a cart or large bier, if either were employed.

A third mode of use is indicated by two drinking vessels placed near the feet, with fragments of larger vessels near the head (where there may also have been part of an alabastron, a squat, rounded jar with relatively narrow mouth, possibly with a smaller vessel stopping its mouth). The vessels had also been brought into the tomb (unless repositioned near the corpse as part of a rearrangement of existing material) and utilized before final deposition. Other vessels and bones known to have been found on the floor also contributed to the production of context through rearrangement of pre-existing material.

The material culture gathered with the corpse implies interlinked sequences of human agency stretching out from the tomb and back in time to the procession, to the preparation of the dead, to the gathering of the mourners and the collection of the objects. The knowledge mobilized and articulated through these materials entails moments of use, exchange and production, each moment of material action linking the living to the dead, the past to the present, collectively mobilized with the intention of burying the dead. However objects were not only chosen because of meanings and memories that could be revitalized through their display or use. They were also employed actively in funerary performance as props to refer to the participants and their relationship to the dead and her successors. Thus the performance from beginning to end was a negotiated improvisation and the deposition which ended it crafted a meaningful tableau brimming with references to the participants and their actions in creating it.

In the example at Routsi we can grasp the essence of some of those references, even if the detail of individual action escapes us. We can reconstruct nodes on the timeline of the funeral through the actions implied by the material (cf. Olivier 1999, esp. 120-2). First were the events before the funerary group began to move toward the tomb. The mourners gathered; acts of preparation were carried out on the corpse; in this case adornment with few items: a necklace, and perhaps a bracelet. We can infer other acts: dressing the corpse in organic materials or perhaps wrapping the body in a shroud. Evidence from other tombs reveals that the dress of the corpse (or the shroud) was sometimes enhanced by attaching gold foil cut-outs or spindle whorls (Iakovidis 1977). The regular presence of alabastra in tombs, as in the present example, hints at a ritual of anointing or the use of oils in the preparation of the corpse (Cavanagh 1998), though, since the vessels reached the tomb, anointing possibly took place there, perhaps in addition to earlier anointments in the preparation phase. Small items such as knives could also have been fixed as part of the raiment of the corpse during preparation. 
In preparing the body for burial, mourners effected a small transformation that was part of a larger project involving re-negotiating roles and relationships to accommodate the absence of the agency of the newly dead. This process began with the relatively small group engaged in the preparatory phase, but would soon have encompassed those others invited to gaze upon the dead, if there was a laying out phase, and those who witnessed the body during the procession to the grave.

Death is loss, adjustment and opportunity, weight, coping and ambition. Natural processes impose a tempo on human action; in most recent Mediterranean traditions, interment follows with little delay. Those preparing the corpse substituted their own agency for that of the deceased. The washing away of blood or the use of cosmetics to hide the effects of illness could downplay the pain or suffering of the final moments of life to present an idealized and abbreviated account of lived experience. Material enhancements such as special raiment or adornment would highlight the actions of the living to project or display their close relationship with, and obligations to, the deceased person, as well as creative engagements with tradition. These emphases would continue after arrival in the tomb.

In the Routsi example, while we have only two items of adornment placed upon the readied corpse, they are both items of significance. The amber necklace represents conspicuous display of a restricted, imported material (Harding and Hughes-Brock 1974) with a complicated object biography. As Maran (2013) has recently argued, the amber was probably transported to southern England, crafted into composite objects and exchanged several times en route to the Peloponnese, during which period these objects were deconstructed and rearranged, perhaps more than once. Similarly, the sealstones, which had perhaps been threaded into a bracelet, represent a composite object uniting multiple references. In Minoan Crete, sealstones probably originally signified specific individuals or groups and were used for administrative purposes and perhaps also for their amuletic effects (Weingarten 2010). As found in Mycenaean Greece, often in groups rather than singly, their effect was to concatenate past histories, along with perhaps their special powers.

The adornment of the corpse in this first stage already situated the dead in a complex mesh of references whose material manifestation contributed to the spectacle of the funeral. How was this material gathered? Did the dead person 'own' the items and so the inheritors decided a role in the funeral outweighed their interest in retaining the items? Were the items gathered from among the mourners, perhaps as a series of single items assembled to create new composite objects? Or were some of them retrieved from prior burials, to be used to materialize the incorporation of the newly dead among the ancestors? Each of these alternative hypotheses highlights different actors: the first, a close-knit group of inheritors; the second, a wider community of mourners; and the third, the ancestors. All three groups may play significant roles: the first in driving the performance, while the second asserted their role through participation (the introduction of objects, some with complex histories, was one mode of participation). A third group, the ancestors, could also have been made to seem active in the process by the use of ancestral objects retrieved from tomb contexts.

Once prepared, the body was transported to the grave, perhaps after a period of limited or open accessibility (akin to 'lying in state'). Transport of body and materials to the grave required participation and almost inevitably took the form of a procession (Boyd forthcoming a). A staged journey from dwelling (or other building in the lived environment) passed through a familiar landscape to cemetery and tomb. Reflective items such as amber and gold (present among the sealstones) would have glittered conspicuously in the sunlight - or torchlight. Metal objects eventually deposited with the dead would also have reflected light. Several people would have been actively engaged with the transport of the corpse and the other materials, perhaps aided by a bier or cart. As others joined the procession, they could have contributed additional material; if some material were retrieved from other tombs, this may have occurred as the party paused at significant points on the journey.

Turning to the tomb interior we see evidence of material engagement at different times and for different reasons. As I have argued elsewhere (Boyd forthcoming b), mourners would engage with the material in a tomb in at least three different instances. First, prior to procession and burial, the tomb may have been prepared to receive the new burial. Unless the tomb had been newly built, it would already contain skeletal and funerary material associated with the memory of past acts. Preparing for the new interment may have included the rearrangement of existing material, both to make space for the new interment and also to allow sufficient space for a some of the mourners to move around the corpse. It has wrongly been assumed that these acts would have been entirely focused on practical tasks of making space, the detritus of past acts little more than rubbish to be swept aside. 1 However, more recently close study of burial practices shows that each instance of engagement with the material remains of the past was one of rediscovery and reincorporation. 
The tomb at Routsi described here has an unusually complex architectural history (Boyd 2002; Korres 1982) that led, by the time of the last burial discussed here, to an uneven interior of benches, platforms and sunken areas (the latter though perhaps by now filled in). Three or four previous interments had already been gathered and reinterred in a pit (pit 2), above which a subsequent interment had been made (the other pit contained a single inhumation). Pottery not immediately associated with burial contexts was found throughout the chamber, entrance and dromos. Two ivory pyxides and an ivory comb were found near the entrance, and arrowheads were lying on the surface. Korres (1982) noted scattered bones on the floor. It is not easy to confirm that these arrangements were contemporary with the final burial (they may post-date it). However, because (as will be outlined below) later activities usually involved disaggregation of the primary burial context, which did not occur here, we might assume these arrangements were part of the layout of the tomb immediately prior to this final burial, the apparent final act in the tomb.

One remarkable find was a large, richly decorated jar placed upside-down on the covering slabs of pit 2 (Fig. 3 ). The pit had initially been used to re-inter material gathered during the disaggregation of three or four earlier burial contexts. A later burial had then been placed directly on top, perhaps an expression of relationships among the dead. Subsequently the lower half of this skeleton and its associated material had itself been disarticulated, although the upper half was preserved intact. As with the latest burial, the upper burial of pit 2 wore an amber necklace and had been interred with weapons and a mirror. Amber necklaces are extremely rare beyond the Mycenae shaft graves (Harding and Hughes-Brock 1974; Maran 2013); the occurrence of two within a single tomb points to a conscious imitation linking these two burial performances, as does the inclusion of the mirror in each context.

The most conspicuous aspect of the burial on the floor was the inclusion of six swords (with four smaller blades);: these are less conspicuously reflected in the pit, where daggers but no swords were found. Five of the six swords are Type A (Harrell 2010, 118 table 11), and one is Type D. The older Type A swords were anachronistic by the time of the burial, a phenomenon observed in other tombs in the south-west Peloponnese (Harrell 2010). Drawing on Bennet's earlier observations (2004), Harrell (2010, 135) emphasizes the memory of past acts projected onto 'martial culture', and that a lengthy biography may have been favoured - to which the performance of incorporation in a grave context would be a powerful addition. Prior, or even recurring, use in tomb contexts may have formed part of that biography. The six swords of the floor burial may, of course, have been gathered from among the mourners, or from the possessions of the dead, or from other tombs, but one or more swords (perhaps including one sword which had been bent beyond use) may have first formed part of the upper burial context in pit 2, now appropriated as an act of engagement with the material past of the tomb, part of the rearrangements of the interior for the new burial.

One further link between the floor burial and pit 2 was noted by Rehak and Younger (2000), who observe that most of the sealstones at the wrist of the floor burial form pairs, but that one of those that does not may be paired with one of the sealstones found with the relocated burials in the bottom of pit 2 . Given the disarticulation of the lower half of the upper pit 2 burial, it is possible that some (or all) of the sealstones fashioned into a bracelet around the wrist of the latest burial may in fact have been recovered from pit 2 as part of that process of disarticulation and reused for the new interment. While none of these observations is conclusive, given the strong material resemblance between the floor burial and that in pit 2, it is clearly possible, and perhaps likely, that some material pre-existing in the tomb was redeployed in the final burial.

During the depositional phase, the body was set on the floor of the tomb and most of the material was placed on the right side. Besides the adornment of the corpse, probably largely set during the preparation phase, and the 'martial culture' (and the mirror) set beside the corpse during interment, a third category of intentional deposition is represented by pottery vessels. Alabastra have already been mentioned in relation to anointing. The other vessels directly associated with this burial were not separately identified by the excavator; however, they include at least two drinking vessels. The drinking shapes and those which might be associated with wine, such as the large jar placed upside-down (and hence, empty) on top of pit 2, suggest toasting or libation ceremonies. These may have been the last act by mourners over the newly deposited body, as the drinking vessels were incorporated into the final funerary tableau as markers of the final actions at the grave. The vessels further emphasized distant connections and object biographies: among impressively decorated vessels, many imitated Cretan styles, while others may have been Cretan imports (Korres 1982; Lolos 1985, 209; Marinatos 1957a).

\section{The transformation of the dead}

With the funeral complete, the dead person was left surrounded by material echoes of things past: the actions of the funeral, the actions that brought material into the tomb and the actions that rearranged the wider tomb 
context. Human action is a continuum and the place of material culture in it must be understood as such. Nevertheless, in the quiet of the grave, for a while, things stopped. The entrance was walled up, animal ingress prevented. Darkness fell; time passed.

In the case of the last burial in Routsi tomb 2, the archaeological story ends there. At some point, probably quite soon afterwards, the tomb collapsed (or was deliberately brought down). It seems no mourners or descendants returned to this tomb. This is unusual: for almost all Mycenaean burials further activities ensued (Boyd 2002, 84-87; Boyd forthcoming b; Cavanagh 1978; Cavanagh and Mee 1998, 76; Gallou 2005, 113-14; Wells 1990, 135-36; for a contrary view, Papadimitriou 2001, 178-179). At some point after the dissolution of the flesh a group of mourners would return to the tomb: the funerary tableau would await rediscovery; life would have moved on outside, but as the party stepped back into the tomb, they would have been confronted by the material traces of the funeral, a snapshot of the past waiting to be reincorporated into the present. The mourners would have been reshaped by their experiences and the passage of time outside the tomb, yet inside the tomb that passage was marked by the transformation of the corpse from an idealized simulacrum of the living person to a set of bones still clothed as for burial. The mourners would set about further rearrangement of the burial context: bones would be disarticulated, perhaps gathered in pits or niches; items would be moved to new positions, some might be broken or bent, some pottery might be removed and reused or broken in the dromos, and some items might be removed altogether. The effect was to de-emphasize the individual and his or her own singular context, re-incorporating the remains among the mixed ancestral materials within the tomb. In the tomb at Routsi such actions performed upon earlier burials are visible in the things found in the bottom of pit 2: the mixed remains of at least four dead, with some material remnants of the funerary activities, including silver vessels, fragments of gold leaf, further sealstones and some broken pottery.

While the details of such actions would have varied from tomb to tomb (for a detailed consideration of an entire cemetery, see Boyd 2014), all of this activity was transformational. The meanings of the bones and objects were being transformed by ongoing acts of re-ordering. The recognizable bones that recall the individual are transformed into anonymous remains of ancestors, part of the assemblage of material culture within the tomb. Crafted objects, similarly, lose some of their association with one burial to become part of the collective resource of the tomb. At the same time, objects or bones could be removed, returned to the everyday world or introduced into other tombs where they might carry earlier associations with them. Similarly, new objects or bones could be introduced into the tomb, bringing new associations of other places or other tombs with them.

The transformation brought about by the mourners, prompted by the physical transformation in the state of the corpse, also addressed changes in kinship and community relationships that had been negotiated and effected outside the tomb. In individual and collective agency they enacted these relationships by re-arranging material referents in the tomb. The dead, no longer active among them, had to be reimagined as part of the ancestral corps. In this way, the agency of the dead was reconfigured as an idea whose presence could be called to mind when required. This was represented materially by the new arrangements in the tomb, which produced new possibilities for material performance, couched now in terms of the ancestors and not of the individual.

In this manner, the entire range of activities associated with Mycenaean tombs can be seen as meaningful, part of considered strategies and ongoing engagements with funerary contexts. Mycenaean funerary spectacles were intended to foreground understandings of the history of the tomb and its inhabitants, as presented (and actively manipulated) by those claiming and remaking their relationships with each other through the treatment of the individual and collective dead. The performances involving the preparation and dressing of the corpse, and in large part the procession, laid emphasis on the newly dead and provided opportunities for those claiming descent, inheritance or other connection to materialize multiple relationships through the manipulation and augmentation of the spectacle of presenting the corpse for burial.

On the other hand, the acts of interment and incorporation of the corpse within the tomb usually involved intervention and considerable reorganization of the existing material disposition of the interior, disarticulating prior contexts and re-crafting the interior as an amalgam of the present funeral and the remains of past rituals. They presented the place of the dead (and, through her, the living) in an ideal relationship with the ancestors. This aspect emphasizes the beginning of the loss of the individuality of the dead, a process signified by the physical transformation of the corpse through decomposition and completed by later rites which again reorganized the material content of the tomb so as to de-emphasize the remains of the individual funeral. Thus two significantly different social aspects of death began to be reconciled in visible ways during the funeral: the loss of the living agent among family, corporate group and wider community; and the transformation of the dead into an accessible member of the ancestral group. These social transformations were achieved primarily through spectacle - and the associated material strategies - that jointly comprised the acts of the funerary performance. 


\section{Acknowledgements}

I would like to thank the editor and staff of Antiquity for permission to reproduce the images used in this article. This paper is based on papers read at the Archaeological Institute of America Annual Meeting in Chicago, 2008, in the Material Culture Laboratory seminar series at the McDonald Institute for Archaeological Research in 2011, and in the main seminar series of the same institute in 2013. I would like to thank all those who commented on these earlier versions. I thank Evi Margaritis for comments on a draft of the current version.

Michael J. Boyd

McDonald Institute for Archaeological Research, University of Cambridge mjb235@cam.ac.uk

\section{Note}

1 This fallacy has arisen out of the search for the pristine, intact burial: past excavators did not prioritise (or record) all contexts equally, but prized the intact burial above all other contexts. This was due to the prioritization of the search for evidence of the elite over the search for all evidence equally; mixed and damaged contexts could simply be explained as the result of the clearance of space, conceived of as lacking significant meaning, or of looting, whether ancient or modern, of little interest as not carried out by the elite. Thus little effort was made to record or interpret contexts other than pristine burials. Indeed, it is astonishing that the term 'swept burials' has entered the literature: equating past burials with rubbish, and according them less interpretative effort than might be expended on an actual pile of rubbish.

\section{References}

Barrett, J. C. 2000. 'A thesis on agency.' In Agency in Archaeology, edited by M.-A. Dobres and J. E. Robb, 61-8. London: Routledge.

Barrett, J. C. 2001. 'Agency, the Duality of Structure, and the Problem of the Archaeological Record.' In Archaeological Theory Today, edited by I. Hodder, 141-64. Cambridge: Polity.

Bennet, J. 2004. 'Iconographies of Value: Words, People and Things in the Late Bronze Age Aegean.' In The Emergence of Civilisation Revisited, edited by J. C. Barrett and P. Halstead, 90-106. Oxford: Oxbow.

Boyd, M. J. 2002. Middle Helladic and Early Mycenaean Mortuary Practices in the Southern and Western Peloponnese. Oxford: Archaeopress.

Boyd, M. J. 2014. 'The Development of the Bronze Age Funerary Landscape of Nichoria.' In KE-RA-MEJA Studies Presented to Cynthia Shelmerdine, edited by D. Nakassis, J. Gulizio and S. A. James. Philadelphia, PA: INSTAP Academic Press.

Boyd, M. J. in press. 'Explaining the Mortuary Sequence at Mycenae.' In Mycenaeans up to Date: The Archaeology of the NE Peloponnese - Current Concepts and New Directions, edited by A.-L. Schallin and I. Tournavitou. Athens: Swedish School.

Boyd, M. J. forthcoming a. 'Fields of Action in Mycenaean Funerary Practices.' In Staging Death: Funerary Performance, Architecture and Landscape in the Aegean, edited by A. Dakouri-Hild and M. J. Boyd.

Boyd, M. J. forthcoming b. 'Becoming Mycenaean? The Living, the Dead and the Ancestors in the Transformation of Society in the Second Millennium BC in Southern Greece.' In Death Shall Have No Dominion: The Archaeology of Mortality and Immortality - A Worldwide Perspective, edited by C. Renfrew, M. J. Boyd and I. Morley. Cambridge: Cambridge University Press.

Cavanagh, W. G. 1978. ‘A Mycenaean Second Burial Custom?' Bulletin of the Institute of Classical Studies 25: 171-2.

Cavanagh, W. G. 1998. 'Innovation, Conservatism and Variation in Mycenaean Funerary Ritual.' In Cemetery and Society in the Aegean Bronze Age, edited by K. Branigan, 103-14. Sheffield: Academic Press.

Cavanagh, W. G. and C. B. Mee. 1998. A Private Place: Death in Prehistoric Greece. Jonsered: Paul Åströms Förlag.

Dakouri-Hild, A. and M. J. Boyd, eds. forthcoming. Staging Death: Funerary Performance, Architecture and Landscape in the Aegean. 
DeMarrais, E. 2004. 'The Materialization of Culture.' In Rethinking Materiality: The Engagement of Mind with the Material World, edited by E. DeMarrais, C. Gosden and C. Renfrew, 11-22. Cambridge: McDonald Institute for Archaeological Research.

DeMarrais, E., L. J. Castillo, and T. Earle. 1996. 'Ideology, Materialization, and Power Strategies.' Current Anthropology 37: $15-31$.

Dickinson, O. T. P. K. 1977. The Origins of Mycenaean Civilisation. Göteborg: Paul Åströms Förlag.

Gallou, C. 2005. The Mycenaean Cult of the Dead. Oxford: Archaeopress.

Giddens, A. 1984. The Constitution of Society: Outline of the Theory of Structuration. Cambridge: Polity Press.

Harding, A. and H. Hughes-Brock. 1974. 'Amber in the Mycenaean World.' Annual of the British School at Athens 69: 14572.

Harrell, K. M. 2010. 'Mycenaean Ways of War: The Past, Politics and Personhood.' PhD diss., University of Sheffield.

Harrell, K. forthcoming. 'Resurrections: The Depiction of Martial Culture at LH IIIB Mycenae.' In Technologies of Representation, edited by J. Bennet and M. Peters. Oxford: Oxbow.

Hodder, I. 1982. Symbols in Action: Ethnoarchaeological Studies of Material Culture. Cambridge: Cambridge University Press.

Hodder, I. 2006. 'The Spectacle of Daily Performance at Çatalhöyük.' In Archaeology of Performance: Theaters of Power, Community and Politics, edited by T. Inomata and L. S. Coben. Lanham, MD: AltaMira Press.

Iakovidis, S. 1977. 'On the Use of Mycenaean “Buttons”.' Annual of the British School at Athens 72: 113-19.

Inomata, T. and L. S. Coben, eds, 2006. Archaeology of Performance: Theaters of Power, Community and Politics. Lanham, MD: AltaMira Press.

Korrés, G. S. 1982. 'Burial Customs in Tholos Tomb 2 at Routsi /Myrsinochori.' In Concilium Eirene: 16th International Eirene Conference, edited by P. Oliva and A. Frolíkova, Vol. 3, 91-7.

Lolos, Y. G. 1985. 'The Late Helladic I Pottery of the Southwestern Peloponnesos and its Local Characteristics.' PhD thesis, University of London.

Maran, J. 2013. 'Bright as the Sun: The Appropriation of Amber Objects in Mycenaean Greece.' In Mobility, Meaning and the Transformations of Things, edited by H. P. Hahn and H. Weiss. Oxford: Oxbow.

Marinatos, S. N. 1957a. 'Excavations near Pylos, 1956.' Antiquity 31: 97-100.

Marinatos, S. N. 1957b. 'A Magnificent Find of Homeric Gold and Gems from an Unplundered Tomb at Nestor's Pylos, Including Superb Inlaid Daggers,' Illustrated London News, 6 April: 540-3.

Morris, I. 1994. 'Archaeologies of Greece.' In Classical Greece: Ancient Histories and Modern Archaeologies, edited by I. Morris, 8-47. Cambridge: Cambridge University Press.

Olivier, L. 1999. 'The Hochdorf "Princely" Grave and the Question of the Nature of Archaeological Funerary Assemblages.' In Time and Archaeology, edited by T. Murray. London: Routledge.

Papadimitriou, N. 2001. Built Chamber Tombs of Middle and Late Bronze Age Date in Mainland Greece and the Islands. Oxford: Archaeopress.

Pearson, M. and M. Shanks. 2001. Theatre/Archaeology. London: Routledge.

Rehak, P. and J. Younger. 2000. 'Minoan and Mycenaean Administration in the Early Late Bronze Age: An Overview.' In Administrative Documents in the Aegean and their Near Eastern Counterparts: Proceedings of the International Colloquium, Naples, February 29-March 2, 1996, edited by M. Perna, 277-301. Naples: Ministero per i Beni Culturali e Ambientali, Ufficio Centrale per i Beni Archivistici.

Renfrew, C. 2004. 'Towards a Theory of Material Engagement.' In Rethinking Materiality: The Engagement of Mind with the Material World, edited by E. DeMarrais, C. Gosden and C. Renfrew, 23-31. Cambridge: McDonald Institute for Archaeological Research. 
Robb, J. 2004. 'The Extended Artefact and the Monumental Economy: A Methodology for Material Agency.' In Rethinking Materiality: The Engagement of Mind with the Material World, edited by E. DeMarrais, C. Gosden and C. Renfrew, 131-9. Cambridge: McDonald Institute for Archaeological Research.

Robb, J. 2010. 'Beyond Agency.' World Archaeology 42: 493-520.

Schechner, R. 1993. The Future of Ritual: Writings on Culture and Performance. London: Routledge.

Schliemann, H. 1878. Mycenae: A Narrative of Researches and Discoveries at Mycenae and Tiryns. London: John Murray.

Shanks, M. and C. Tilley. 1987. Social Theory and Archaeology. Cambridge: Polity.

Shanks, M. and C. Tilley. 1992. Re-Constructing Archaeology: Theory and Practice. 2nd edn. London: Routledge.

Thomas, J. 1996. Time, Culture and Identity: An Interpretative Archaeology. London: Routledge.

Weingarten, J. 2010. 'Minoan Seals and Sealings.' In The Oxford Handbook of the Bronze Age Aegean, edited by E. Cline, 317-28. Oxford: University Press.

Wells, B., 1990. 'Death at Dendra: On Mortuary Practices in a Mycenaean Community.' In Celebrations of Death and Divinity in the Bronze Age Argolid: Proceedings of the Sixth International Symposium at the Swedish Institute at Athens, 11-13 June, 1988, edited by R. Hägg and G. C. Nordquist, 125-40. Stockholm: Svenska Institutet i Athen. 